\title{
Brain abscess due to Streptomyces griseus
}

\author{
P. R. R. CLARKE, G. B. R. WARNOCK, R. BLOWERS, AND MARGARET \\ WILKINSON \\ From Middlesbrough General Hospital, Sedgefield General Hospital, and the Public Health Laboratory and \\ Central Clinical Laboratory, Middlesbrough
}

Fungous diseases of the central nervous system are rare, the least uncommon being cryptococcosis, mucormycosis, cladosporiosis, and nocardiosis (Mariat, 1957). Our search of the literature on fungous diseases of man has failed to reveal any previously reported case of streptomyces infection of the brain. Streptomyces are widely present in soil, and on culture are said to emit an odour suggestive of a newly dug grave or a damp cellar (Lewis, Hopper, Wilson, and Plunkett, 1958). They have a fine, branched, non-fragmenting mycelium and may produce antibiotics, namely, streptomycin ( $S$. griseus), chloramphenicol ( $S$. venezuelae), neomycin ( $S$. fradiae), and oxytetracycline ( $S$. rimosus).

\section{CASE HISTORY}

A woman aged 53 visited her doctor on 24 November 1961 complaining of pain on the right side of the forehead. Frontal sinusitis was diagnosed and she was given codeine tablets. The symptoms apparently abated until a month later when she again had severe frontal headache, associated this time with swelling of the face. Conservative treatment was given but the headache became worse and she complained of double vision. An ophthalmologist who was called in consultation noted right-sided proptosis, chemosis, ptosis, and limitation of eyeball movements in all directions. It was considered that orbital cellulitis was present and she was given tetracycline, $250 \mathrm{mg}$. sixhourly. After $6 \mathrm{~g}$. of tetracycline had been given the proptosis disappeared and treatment was stopped. She then began to vomit and became progressively drowsier. On 19 January 1962 she was admitted as an emergency case to Sedgefield General Hospital where she was found to be almost unrousable. She had marked neck stiffness, right-sided ptosis and external ophthalmoplegia, and appeared not to feel painful stimuli applied to the right side of the face in the distribution of the sensory division of the trigeminal nerve. Her temperature fluctuated between $97^{\circ}$ and $99 \cdot 8^{\circ} \mathrm{F}\left(36 \cdot 1^{\circ}-37 \cdot 7^{\circ} \mathrm{C}\right)$. The blood white-cell count was 12,400 per c.mm. (76\% neutrophils, $1 \%$ eosinophils, $20 \%$ lymphocytes, and $3 \%$ monocytes). $X$-ray examination of the chest showed bilateral apical calcification but no active disease. Skull radiographs were normal. Lumbar puncture produced turbid fluid containing 2,240 polymorphs per c.mm., $195 \mathrm{mg}$. protein per $100 \mathrm{ml}$., $43 \mathrm{mg}$. sugar per $100 \mathrm{ml}$., and an increased quantity of globulin. The Wassermann reaction in the spinal fluid was negative and the Lange curve 4455555432. Culture of this yielded no growth. She was treated with intramuscular sulphathiazole ( $1 \mathrm{~g}$. six-hourly) and penicillin ( 2 mega-units six-hourly). On 26 January she was found to have right hemiplegia with increased tendon reflexes and an absent right corneal reflex and was transferred to the neurosurgical unit at the Middlesbrough General Hospital. She was so drowsy that full cooperation in the neurological examination could not be obtained. The provisional diagnosis at that time was orbital cellulitis and frontal-lobe abscess on the right side. The cause of the hemiplegia was thought to be pressure of the left cerebral peduncle against the tentorial edge. Treatment was continued with penicillin 1 mega-unit sixhourly; streptomycin, 1 g. every 12 hours, was substituted for the sulphadiazine. On 27 January ventriculography was performed under local anaesthesia. The pressure in the lateral ventricles was $70 \mathrm{~mm}$. of cerebrospinal fluid. Radiography showed dilatation without displacement of the lateral and third ventricles. With the patient in the face-down position air was seen to enter the aqueduct but not to pass through it. Ten thousand units of penicillin were injected into the left lateral ventricle. The ventricular fluid contained 650 red cells per c.mm., 4 lymphocytes per c.mm., $80 \mathrm{mg}$. protein, $70 \mathrm{mg}$. sugar, and 720 mg. chloride per $100 \mathrm{ml}$. The next day the patient was much better and was able to answer simple questions. Another intraventricular injection of 10,000 units of penicillin was given. On 29 January further improvement was evident and it was noted that nystagmus was presen $t$ on lateral, upward, and downward gaze but was most marked on looking to the right. When the patient opened her mouth the lower jaw deviated to the right. In view of the nystagmus and the ventriculographic findings it was decided to explore the posterior fossa. On 30 January under general anaesthesia (Dr. H. L. Leaming) a burr hole was made over the right lobe of the cerebellum which was found to be bulging. A small opening was made in the dura and at a depth of $3 \mathrm{~cm}$. a thick-walled abscess was entered with a brain cannula. Six $\mathrm{ml}$. of very thick pus was aspirated, after which a mixture of 10,000 units penicillin, $50 \mathrm{mg}$. streptomycin, and $0.5 \mathrm{ml}$. Steripaque (Clarke, Langmaid, and Wray, 1962) was injected, the total volume of the injected substances being $2 \mathrm{ml}$. A posterior-fossa decompression operation was then performed on the right side. Post-operative radiography showed the extent of the abscess (Fig. 1). There was considerable dental sepsis and Mr. E. J. R. Morgan reported: 


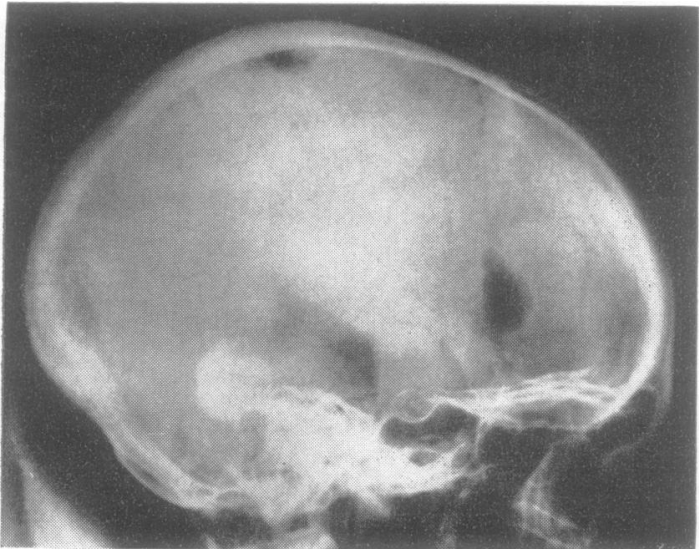

FIG. 1. Post-operative radiograph showing the abscess cavity filled with opaque medium. Air remaining from the ventriculogram is also visible.

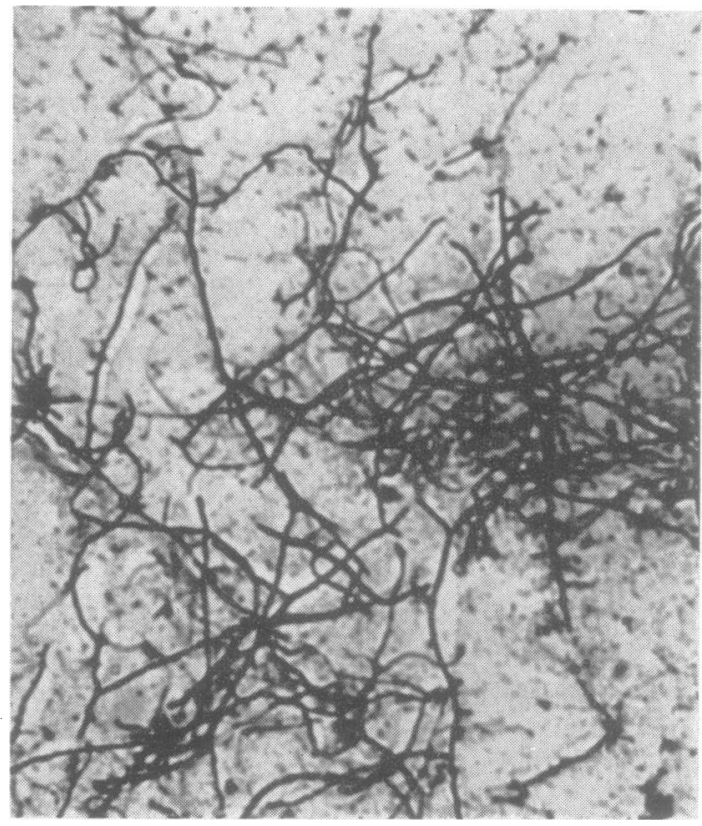

FIG. 3. Gram-stained smear from primary growth. The branching of the mycelium is clearly seen.

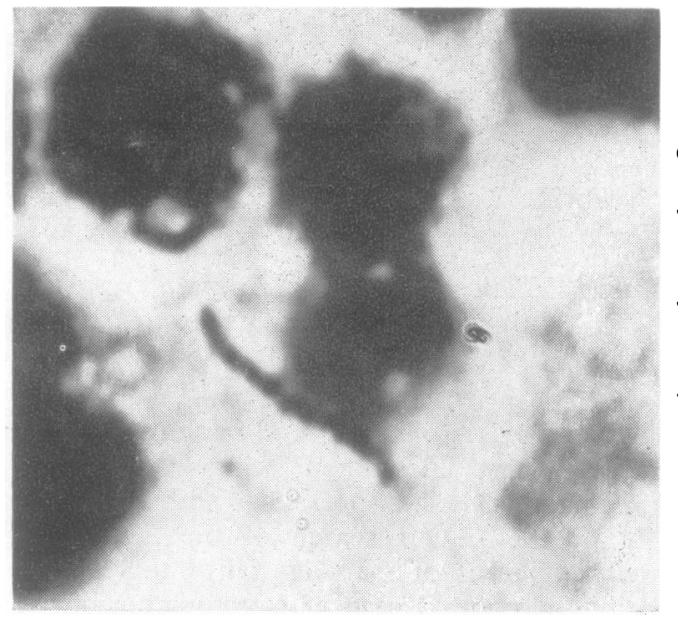

FIG. 2. Direct smear of pus from abscess (Gram's stain). A prolonged search revealed only a few pieces of mycelium such as this.

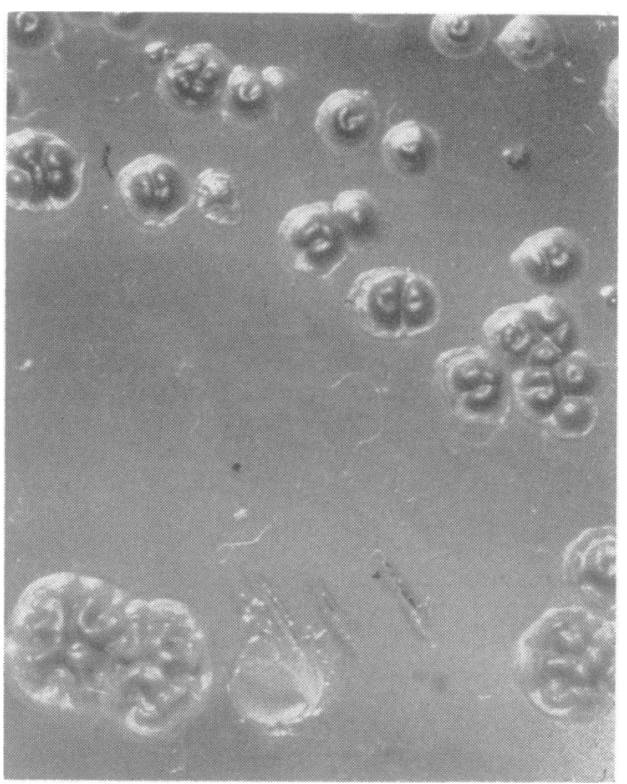

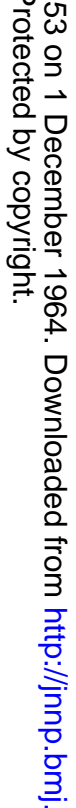

FIG. 4. Subculture from primary growth, after seven days ${ }^{\circ}$ aerobic incubation on blood agar at $22^{\circ} \mathrm{C}$. The colonies in the more crowded part of the plate show the appearances $\frac{}{3}$ of isolated colonies at three days. 
'The teeth are dirty, with deep pockets round the lower incisors and canines. There is a lot of calculus round these teeth. Radiographs show chronic apical infection but there are no discharging sinuses or anything to suggest that the teeth have ever been acutely infected.' A review of the case at this stage led us to feel that the sequence of events had been cavernous sinus thrombosis due to spread of infection by way of the veins from the teeth of the upper jaw, with secondary extension of sepsis from the cavernous sinus along venous channels to the cerebellum. The cornea of the right eye became dry and a lateral tarsorrhaphy was performed by Mr. R. Cowley.

Direct microscopy of the pus showed beaded, nonfragmented strands of mycelium (Fig. 2). After seven days' aerobic incubation on blood agar, minute colonies appeared; smears showed the branching, filamentous nature of the organism (Fig. 3). Three weeks' asrobic and anaerobic incubation yielded no other growth. Subcultures of the organism grew more quickly (Fig. 4); growth was rather better at $22^{\circ}$ than at $37^{\circ} \mathrm{C}$. The organism was sensitive in vitro to penicillin, streptomycin, chloramphenicol, and the tetracyclines. At the Mycological Reference Laboratory of the London School of Hygiene and Tropical Medicine Dr. I. G. Murray identified it as a member of the genus Streptomyces, and sent it for further examination to the Laboratory of Professor Waksman, of Rutgers University, New Brunswick. There it was assigned to the Streptomyces griseus group (as Streptomyces coelicolor $)^{1}$, although it did not itself produce antibiotics.

On 2 March 1962 all the patient's teeth were extracted. Culture of these did not yield streptomyces. On 5 March the administration of streptomycin was stopped but penicilin was given until $23 \mathrm{March}$, when streptomycin was again given and continued until 24 April. The first course of streptomycin totalled $48 \mathrm{~g}$. and the second $55 \mathrm{~g}$. The total dose of penicillin was 280 mega units.

The patient's condition steadily improved and repeated radiographs demonstrated shrinkage of the abscess. On 17 June she left hospital and in July 1963 she was finally discharged from out-patient attendance. At that time she was living a full life and was able to do all her household work. Residual signs were an absent corneal reflex on the right, hypalgesia on the right side of the face, paralysis of the motor division of the right trigeminal nerve, and a slight tendency to deviate to the right when walking. Radiological examination showed that the abscess had shrunk to a mass the size of a pea.

\section{DISCUSSION}

This patient had cavernous sinus thrombosis, cerebellar abscess, and meningitis developing over a period of two months. As in many other cases of fungous disease of the nervous system some doubt must exist as to whether or not the organism isolated

\footnotetext{
${ }^{1}$ The organism is no 1145 Streptomyces coelicolor in the type collection at the Department of Mycology, London School of Hygiene and Tropical Medicine, Gower Street, London, W.1.
}

was the primary pathogen. We think it was, for the following reasons: first, it was the only organism isolated and it did not itself produce antibiotics that might have exterminated pyogenic bacteria; secondly, the slow course of the illness was quite unlike that associated with the development of cavernous sinus thrombosis and brain abscess due to bacterial infection.

Mariat (1958) in his review of fungous diseases does not mention Streptomyces griseus in a list of streptomyces pathogenic to man. But accurate identification has not always been carried out: Kohn, Tager, Siegel, and Ashe (1951) described a case in which an unnamed species of streptomyces was found on blood culture three times in association with a lung infection.

In this case systemic penicillin and streptomycin combined with intraventricular injections of penicillin and injection of streptomycin and penicillin into the abscess after aspiration of pus brought about a cure. Excision of the abscess did not appear to be indicated in view of the satisfactory response to conservative treatment.

The fact that the organism could not be recovered from the teeth does not absolve them from being the source of the infection, for large doses of antibiotics had been given before the dental clearance was performed. There was abundant evidence of gross, chronic infection of the teeth.

\section{SUMMARY}

A case of cavernous sinus thrombosis and cerebella abscess from which Streptomyces griseus was isolated is described. Cure followed treatment with antibiotics and aspiration of the abscess.

We acknowledge the help received from Dr. I. G. Murray and Dr. Ruth E. Gordon in identifying the organism and from Dr. S. Wray and Dr. A. K. Lamballe with the photographs.

\section{REFERENCES}

Clarke, P. R. R., Langmaid, C., and Wray, S. (1962). The use of micropaque barium sulphate in the treatment of abscesses of the brain. Neurochirurgia (Stuggt.), 4, 211.

Kohn, P. M., Tager, M., Siegel, M. L., and Ashe, R. (1951). Aerobic actinomyces septicemia. Report of a case. New Eng!. J. Med., 245, 640 .

Lewis, G. M., Hopper, M. E., Wilson, J. W., and Plunkett, O. A. (1958). An Introduction to Medical Mycology, p. 248. Year Book Publishers, Chicago.

Mariat, F. (1957). Sur le diagnostic mycologique des principales mycoses du système nerveux central. Sem. Hôp. Paris. Path. et Biol., n.s. 5, B281 (P. et B. 901).

Mariat, F. (1958). In Fungous Diseases and their Treatment, edited by R. W. Riddell and G. T. Stewart, p. 114. Butterworth, London. 